Abstract

\title{
Novel Applications for Monitoring and Management Codling Moth Resistance ${ }^{+}$
}

\author{
Martina Kadoić Balaško ${ }^{1, *}$, Renata Bažok ${ }^{1}$, Katarina M. Mikac ${ }^{2}$, Hugo A. Benítez ${ }^{3}$, Darija Lemic ${ }^{1}$ and Ivana \\ Pajač Živković 1
}

Citation: Kadoić Balaško, M.; ažok, R.; Mikac, K.M.; Benítez, H.A.; Lemic, D.; Pajač Živković, I. Novel Applications for Monitoring and Management Codling Moth Resistance, in Proceedings of the 1st International Electronic Conference on Entomology, 1-15 July 2021, MDPI: Basel, Switzerland, doi:10.3390/IECE-10683

Published: 15 July 2021

Publisher's Note: MDPI stays neutral with regard to jurisdictional claims in published maps and institutional affiliations.

Copyright: () 2021 by the authors. Submitted for possible open access publication under the terms and conditions of the Creative Commons Attribution (CC BY) license (http://creativecommons.org/licenses /by/4.0/).
1 Department for Agricultural Zoology, Faculty of Agriculture, University of Zagreb, Svetošimunska 25, 10000 Zagreb, Croatia

2 Centre for Sustainable Ecosystem Solutions, School of Earth, Atmospheric and Life Sciences, Faculty of Science, Medicine and Health, University of Wollongong, Wollongong 2522, Australia

3 Laboratorio de Ecología y Morfometría Evolutiva, Centro de Investigación de Estudios Avanzados del

Maule, Universidad Católica del Maule, Talca 3466706, Chile

* Correspondence: mbalasko@agr.hr

+ Presented at the 1st International Electronic Conference on Entomology (IECE 2021), 1-15 July 2021; Available online: https://iece.sciforum.net/.

\begin{abstract}
Codling moth (CM), Cydia pomonella L., is the most important insect pest of the apple and has a cosmopolitan distribution. Over $70 \%$ of insecticide treatments in apple orchards are currently used to control CM populations. The intensive use of chemical-based insecticides to control CM has resulted in resistance to several groups of synthetic insecticides worldwide. Therefore, monitoring resistant CM populations is of great importance for effective management and control. In this study, we aimed to find a reliable pattern of differences in the type of control method using a population genetic and geometric morphometric approach. Three treatments were studied and included populations from integrated and ecological (susceptible) orchards and laboratory reared non-resistant populations. We used single nucleotide polymorphisms (SNPs) markers for detailed whole-genome analysis. Ninety-four CM individuals were genotyped. Individuals were subjected to standard population genetic analyzes to determine the alteration of individual alleles as a possible consequence of mutations and the development of resistance. To confirm the genetic results, the forewing morphology of the same ninety-four CM individuals was examined using geometric morphometric techniques based on the venation patterns of 18 landmarks. The preliminary results showed that there is a reliable pattern of differences related to the type of control practice. The use of these techniques (i.e. SNPs and geometric morphometrics) to detect resistant variants is a completely new approach and provides new insights into a very important area of codling moth control.
\end{abstract}

Keywords: Cydia pomonella; SNPs; geometric morphometrics; monitoring techniques; resistance 